\title{
Control of Wound Field Synchronous Motor Integrated with ZSI
}

\author{
Genki Tajima*a) $^{*}$ \\ Nobuyuki Matsui* Fellow, \\ Norimoto Minoshima** Non-member, \\ Takashi Kosaka* \\ Kazuki Tonogi** \\ Toshihiko Yoshida** \\ Senior Member \\ Non-member \\ Non-member
}

(Manuscript received Aug. 15, 2014, revised Dec. 5, 2014)

\begin{abstract}
This paper proposes a novel variable speed motor drive, a wound field synchronous motor (WFSM) drive integrated with a Z-source inverter (ZSI). The proposed WFSM is a nonpermanent magnet machine and employs two field coils as dc field mmf sources. On the other hand, the ZSI has an impedance network that consists of two dc reactors and two capacitors. In the proposed drive, the two field coils of the WFSM act not only as dc field mmf sources but also as dc reactors in the ZSI, resulting in size and cost reductions in the drive system. In order to achieve voltage boost-up and field current controls simultaneously, the control algorithm for this integrated system is examined. Experimental results using a test drive system show that the proposed drive under the proposed control works properly.
\end{abstract}

Keywords: boost-up/field current control, integrated motor and drive circuit system, wound field synchronous motor, z-source inverter

\section{Introduction}

Currently, applications of motors using rare-earth permanent magnets increasing with the aim of increasing efficiency, while reducing size and weight. However, supply constraints and price instability of rare-earth materials have become a problem in recent years. Therefore, research and development of less- or non-rare-earth permanent magnet motors is receiving much attention from industries.

In response to this demand, we proposed a wound field synchronous motor (WFSM) as a non-rare-earth-permanent magnet motor ${ }^{(1)}$. In a WFSM, field fluxes are generated by two field toroidal coils that are wound on stationary field pole cores located at both ends of the motor in the axial direction. This structure enables it to feed current into the field coils without any brushes and slip rings. However, the motor size and cost increase because the field pole cores and the field coils are net additional components that are not present in conventional motors.

On the other hand, in the case of a variable speed drive system where a motor is designed as a high-speed machine under a low-voltage battery drive, a DC-DC boost-up converter inserted between a battery and an inverter is often employed ${ }^{(2)}$. In this case, the size and weight of the motor are expected to reduce while improving its efficiency. However, it is a requirement in the system design to take into account efficiency degradation and cost increase owing to the addition of a DCDC converter.

In this paper, a variable speed drive system shown in Fig. 1

a) Correspondence to: Genki Tajima. E-mail: g.tajima.698@ nitech. jp

* Nagoya Institute of Technology

Gokiso-cho, Showa-ku, Nagoya, Aichi 466-8555, Japan

** Toyota Industries Corporation

8, Chaya, Kyowacho, Obu, Aichi 474-0057, Japan

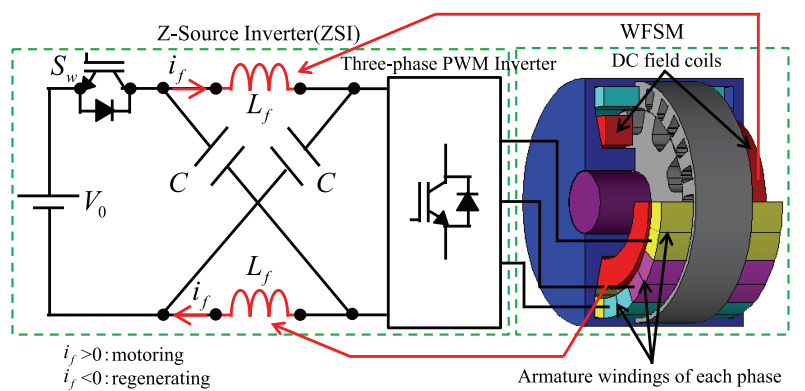

Fig. 1. Proposed drive system configuration

is proposed, where a WFSM is integrated with a Z-source inverter $(\mathrm{ZSI})^{(3)}$. The ZSI has an impedance-network, which consists of two DC reactors $L_{f}$ and two capacitors $C$ and is inserted between a DC voltage source and a three-phase inverter. The ZSI is functioning not only as a three-phase inverter, but also as a DC-DC boost-up converter. However, the size and weight of the bulky DC reactors are disadvantages of the ZSI. This integrated system can solve the drawbacks of the WFSM and the ZSI simultaneously. Specifically, two DC reactors of the ZSI are replaced by two DC field coils of the WFSM as the sharing component in the motor and converter and hence, the proposed drive system is expected to be a solution for size, weight and cost reductions as well as for loss minimization of the total drive system. In the proposed drive system, however, a difficulty lies in its control since the voltage boost-up and field current regulation required for a given operating condition must be satisfied harmoniously. Therefore, the control algorithm for the proposed system is examined as a main objective in this paper. Some experimental studies using a test drive system are conducted and verify that the proposed control algorithm can operate the proposed drive system properly. 


\section{Basic Working Principle of WFSM under Pro- posed Integrated Drive System}

\subsection{Structure and Basic Working Principle of WFSM}

Figure 2 illustrates a general view of a 20-pole/24slot WFSM employing fractional-slot concentrated windings. The main machine part in the middle of the figure is composed of a laminated rotor core with 10 salient poles and a laminated stator core with three-phase armature concentrated windings accommodated in 24 slots. The back yoke core is made of soft magnetic composites (SMC) and forms axial field flux paths flowing into the field pole SMC cores located at both ends of the motor. Each field pole SMC core located at each end of the motor in the axial direction has the toroidal field coil. Figure 3 depicts the field flux paths when only the field coils are energized by a certain DC current. Although the airgap flux density is unipolar, it varies with the rotor position displacement owing to the doubly salient-pole machine nature. As the spatial distribution of gap permeance with respect to the rotor position has AC components, threephase symmetrical AC induced voltage waveforms arise in the three-phase symmetric armature windings by the modulation of the field flux with respect to the rotor position displacement. As a result, the WFSM generates torque by feeding three-phase armature currents with an adequate phase angle against the three-phase induced voltage.

2.2 WFSM Model Given that the AC component of the airgap flux density distribution is sinusoidal, a $d-q$ axis model can be introduced, similar to that in conventional AC motors under three-phase symmetrical sinusoidal current drive.

Assuming that the direction of the field current $i_{f}$ shown in

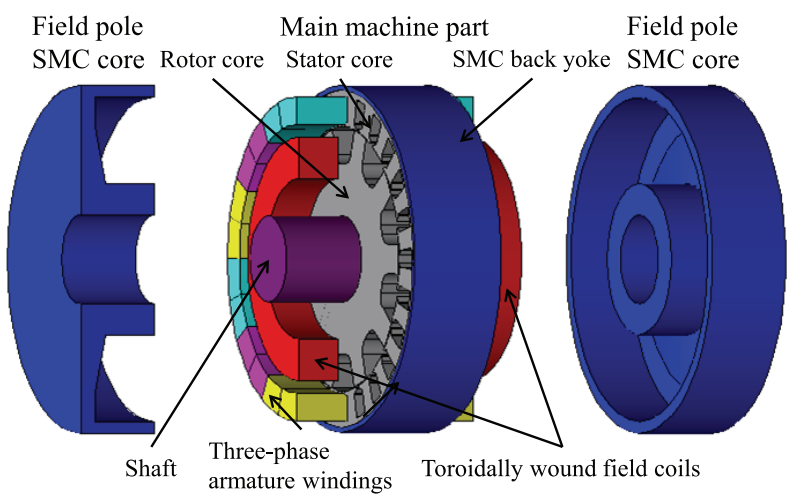

Fig. 2. General view of WFSM

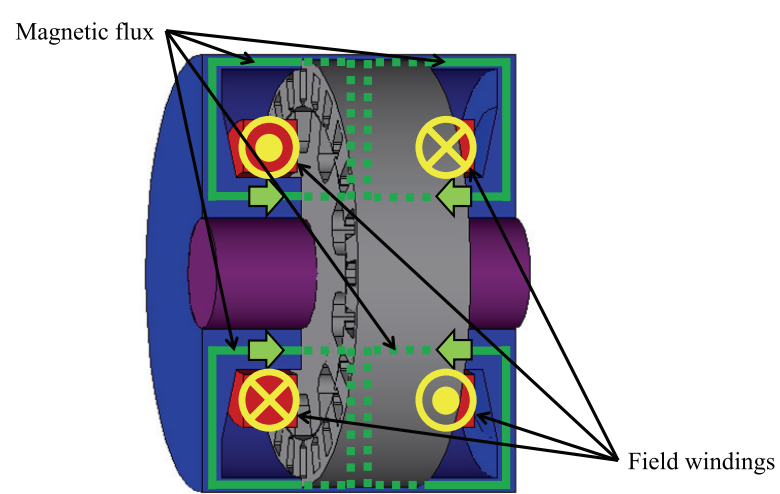

Fig. 3. Field flux paths in WFSM
Fig. 3 is positive and the origin of the rotor position is defined as one where the flux linkage in the U-phase winding reaches its positive maximum, the voltage equation of the WFSM can be expressed in the following manner through the conventional d-q transformation.

$$
\left[\begin{array}{l}
v_{d} \\
v_{q}
\end{array}\right]=\left[\begin{array}{cc}
R+p L_{d} & -\omega L_{q} \\
\omega L_{d} & R+p L_{q}
\end{array}\right]\left[\begin{array}{c}
i_{d} \\
i_{q}
\end{array}\right]+\sqrt{\frac{3}{2}} \omega K i_{f}\left[\begin{array}{l}
0 \\
1
\end{array}\right] \ldots \ldots
$$

The first term in the expression follows the custom in interior permanent magnet motors. The second term $K i_{f}$ in the expression is the amplitude of the AC component of the flux linkage in each phase winding generated by field coil $\mathrm{mmf}$.

The torque equation can be obtained in the following manner:

$$
\tau=\sqrt{\frac{3}{2}} P K i_{f} i_{q}+P\left(L_{d}-L_{q}\right) i_{d} i_{q} \ldots \ldots \ldots \ldots \ldots \ldots
$$

The first term expresses the torque produced by the field flux and the $q$-axis current similar to the magnet torque in permanent magnet motors. The second term is the reluctance torque. The WFSM shown in Figs. 2 and 3 employs fractional concentrated windings, where the reluctance torque expressed in the second term is negligibly smaller than the torque in the first term. Note that the polarity of the torque is determined by the product of the polarities of the field current $i_{f}$ and the $q$-axis current $i_{q}$.

2.3 Motoring and Regenerating Control of WFSM Integrated with ZSI When the rotation direction of the motor is positive $(\omega>0)$, the WFSM integrated with the ZSI shown in Fig. 1 works in the motoring mode. In this mode, the field current $i_{f}$ flows in a direction from the DC power source to the WFSM through the switch $S_{w}$. Given that the direction of this field current is positive $\left(i_{f}>0\right)$, the WFSM, under the motoring mode, generates positive torque by controlling the $q$-axis current so as to be positive based on (2). In the regenerating mode of the WFSM, the field current $i_{f}$ flows in a direction from the WFSM to the DC power source through the switch $S_{w}$. In this case, the direction of this field current is negative $\left(i_{f}<0\right)$ and the WFSM, under the regenerating mode, produces negative torque by controlling the $q$-axis current to be positive based on (2). Thus, the motoring and regenerating modes in the integrated system can be switched by controlling the combination of polarities of both the field and the $q$-axis currents and OFF/ON of the switch $S_{w}$.

\section{Operating Modes of ZSI}

The operating modes of the ZSI are divided into three states in accordance with the switching pattern of the threephase PWM inverter and OFF or ON of the switch $S_{w}$ shown in Fig. 1 for the motoring and regenerating modes, respectively. Here after, it is noted that the inductance of each field coil is $L_{f}$, the resistance of each field coil is $R_{f}$, the capacitance of the capacitors is $C$, each voltage across each impedance-network component is $L_{f} d i_{f} / d t, R_{f} i_{f}$ and $v_{c}$, respectively. Furthermore, the voltage and the current of the DC source are $V_{0}$ and $i_{i n}$, respectively, and the field current is $i_{f}$, the capacitor current is $i_{c}$, the voltage across the inverter leg is $v_{i}$, the current flowing into the inverter is $i_{i}$, 


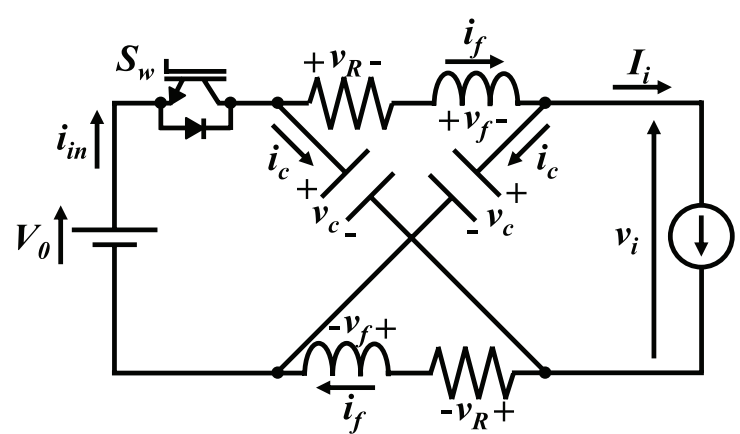

Fig. 4. Equivalent circuit at active state (motoring)

respectively. Each operating mode can be expressed as a corresponding voltage equation regardless of motoring or regenerating. Therefore, the behaviors of the field current and the capacitor voltage are determined accordingly. In the following section, the behavior of the ZSI at each operating mode under a motoring operation is analyzed on the assumption that the PWM carrier frequency of the inverter is sufficiently high compared with the resonance frequency of the impedance-network.

3.1 Active State Figure 4 shows the equivalent circuit at the active state in the motoring mode. Of three possible states, the active state is defined by the inverter outputting a non-zero voltage vector and supplying power to the WFSM. The load side is approximated as a constant current source $I_{i}$ and therefore, the current fed to the inverter $i_{i}$ should be equal to $I_{i}\left(i_{i}=I_{i}\right)$. With regard to time $t$, the beginning time of the active state is defined as $t=0$.

From the voltage equation of impedance-network side at the active state, the time response of field current can be expressed as,

$$
\frac{d i_{f}}{d t}=\frac{V_{0}-v_{c}-R_{f} i_{f}}{L_{f}}
$$

The time response of capacitor voltage can be similarly expressed in the following equation.

$$
\frac{d v_{c}}{d t}=\frac{i_{f}-i_{i}}{C}=\frac{i_{f}-I_{i}}{C}
$$

On the other hand, the current of DC voltage source $i_{\text {in }}$ can be expressed in the following manner according to the relationship between the currents in the ZSI.

$$
i_{\text {in }}=2 i_{f}-I_{i}
$$

In addition, the following condition has to be satisfied because the switch $S_{w}$ is always in the OFF in the motoring mode.

$$
2 i_{f}-I_{i}>0
$$

If (6) is not satisfied, the voltage across the inverter leg $v_{i}$ becomes zero because a part of the current fed to the motor flows through some freewheeling diodes in some switching devices. As a result, this state becomes identical with the shoot through state mentioned later leaving the inverter unable to output the non-zero voltage vector. This state is called the freewheeling diode shoot through state ${ }^{(4)}$ to distinguish it from an intentionally executed shoot through state. In order

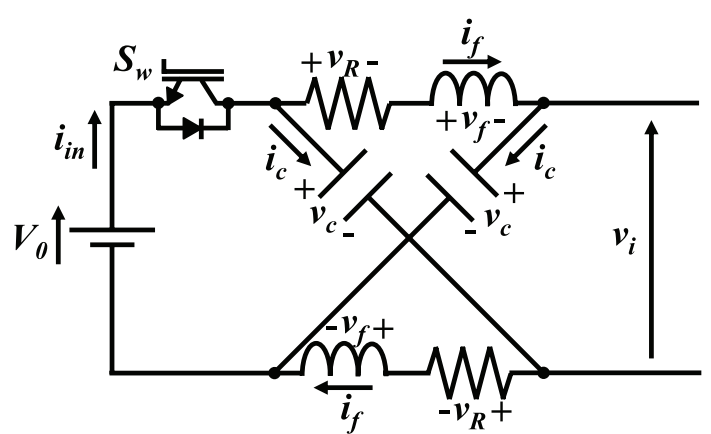

Fig. 5. Equivalent circuit at active zero state (motoring)

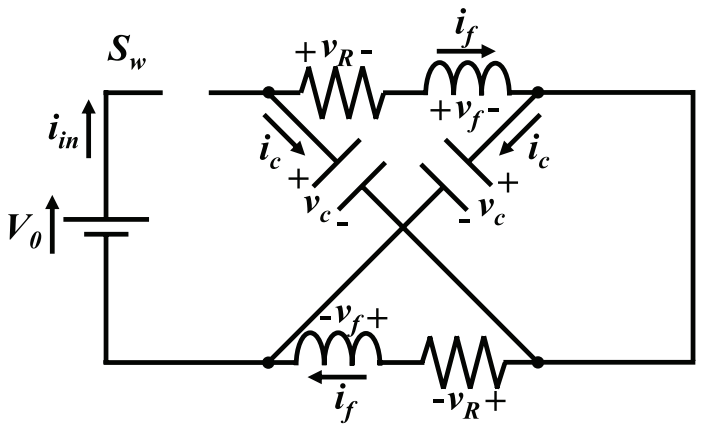

Fig. 6. Equivalent circuit at shoot through state (motoring)

to avoid this state, one of the control restrictions of the ZSI is that the field current $i_{f}$ has to control to meet (6). As long as the field current $i_{f}$ is controlled to meet (6), the voltage across the inverter leg $v_{i}$ meets the following relation.

$$
v_{i}=2 v_{c}-V_{0}
$$

3.2 Active Zero State The equivalent circuit at the active zero state in the motoring mode is shown in Fig. 5. As the inverter outputs the zero voltage vector in the active zero state, the inverter is disconnected from the DC side $\left(i_{i}\right.$ $=0$ ). With regard to time $t$, the changing time to the active zero state is redefined as $t=0$. In this case, as the voltage equation of the impedance-network side is identical with the previously mentioned active state, the time response of field current can be expressed as similar to (3). The time response of capacitor voltage is similarly expressed in (4), but it can be rearranged as the following equation by considering the inverter disconnection.

$$
\frac{d v_{c}}{d t}=\frac{i_{f}}{C}
$$

The voltage across the inverter leg $v_{i}$ can be also similarly expressed in (7).

3.3 Shoot Through State The equivalent circuit at the shoot through state in motoring is shown in Fig. 6. The shoot through state is the state of an inverter arm in short circuit. With regard to time $t$, the time switching to the shoot through state is redefined as $t=0$.

From the voltage equation of impedance-network side, the time response of field current can be expressed as,

$$
\frac{d i_{f}}{d t}=\frac{v_{c}-R_{f} i_{f}}{L_{f}}
$$

The time response of capacitor voltage is obtained from the 
following equation.

$$
\frac{d v_{c}}{d t}=-\frac{i_{f}}{C}
$$

The voltage across the inverter leg at this state can be expressed as $v_{i}=0$.

\section{Control Algorithm for Field Current and Ca- pacitor Voltage}

4.1 Control Principles for Field Current and Capacitor Voltage in Proposed Drive System The basic control principle of the ZSI is examined from the time response expression of field current $i_{f}$ and capacitor voltage $v_{c}$ under each operating state described in the preceding chapter.

The duty ratios $d_{A}, d_{Z}$, and $d_{S}$ of the active state, the active zero state and the shoot through state have the following relation.

$$
d_{A}+d_{Z}+d_{S}=\frac{T_{A}}{T}+\frac{T_{Z}}{T}+\frac{T_{S}}{T}=1 \cdots \cdots \cdots \cdots
$$

The time response of field current at both the active state and the active zero state is determined by (3), and the one at the shoot through state is obtained from (9). The averaging time response of field current during one control interval $T$ is derived from (3), (9) and (11) and given in

$$
\frac{d i_{f}}{d t}=\frac{\left(2 v_{c}-V_{0}\right) d_{S}+V_{0}-v_{c}-R_{f} i_{f}}{L_{f}} \ldots \ldots \ldots \ldots
$$

(12) means that the field current can be controlled by the shoot through state duty ratio $d_{S}$ based on a feedback of field current. Similarly, the averaging time response of capacitor voltage during one control interval $T$ is derived from (4), (8), (10) and (11) and given in

$$
\frac{d v_{c}}{d t}=\frac{-2 i_{f} d_{S}-I_{i} d_{A}+i_{f}}{C} .
$$

(13) implies that the capacitor voltage can be controlled by the active state duty ratio $d_{A}$ based on a feedback of the capacitor voltage under the given shoot through state duty ratio $d_{S}$ as decided by the field current controller. On the other hand, the active state duty ratio $d_{A}$ also has to be determined to meet the requirement for the power control of the WFSM simultaneously. In the proposed drive system, therefore, the capacitor voltage $v_{c}$ and the motor power have to be controlled by only one control input $d_{A}$. In general, this control might be impossible and therefore, we have to introduce another independent control input for the capacitor voltage control. In the right side of (13), the inverter load current $I_{i}$ corresponds to the input power of the WFSM for the given torque and speed condition. As the input power includes not only the output, but also the inverter loss, motor copper and iron losses, the inverter load current $I_{i}$ can be adjusted by the motor copper loss which is controlled by the $d$-axis current with negligible torque change.

4.2 Proposed Capacitor Voltage Control The field and the $d$ - and $q$-axis current controllers are designed so as to respond faster than the capacitor voltage controller because these current responses directly dominate the torque and motor output response. Under this condition, the controller design for achieving the capacitor voltage and the motor output controls simultaneously is examined based on the AC small signal modeling method ${ }^{(5)}$.

Initially, the relation between the input power and the motor output is examined. The input power can be expressed in $v_{i} i_{i} d_{A}$. To explain the control algorithm in simple terms, it can be assumed that the inverter loss and the motor iron loss are negligible compared to the motor copper loss. As a result, the following relation is obtained from (1), (2) and (7).

$$
\left(2 v_{c}-V_{0}\right) i_{i} d_{A}=R\left\{i_{d}^{2}+i_{q}^{2}\right\}+\omega \tau \cdots \cdots \cdots \cdots \cdots
$$

Based on the AC small signal modeling, the variables in the above equation can be defined by using the target value $\left(X^{*}\right)$ and the deviation $(\hat{x})$. In addition, the fine adjustment value of $d$-axis current for the capacitor voltage control mentioned earlier is defined as $\Delta i_{d}$. Under these definitions, each variable is expressed as follows.

$$
v_{c}=V_{c}{ }^{*}+\hat{v}_{c}, i_{q}=I_{q}{ }^{*}, i_{f}=I_{f}{ }^{*}, i_{d}=I_{d}{ }^{*}+\Delta i_{d} \cdots \cdots
$$

Finally, the transfer function from $\Delta i_{d}$ to $\hat{v}_{c}$ is derived from (2), (12), (13) and (14) by substituting the variables expressed in (15) and given in,

$$
G_{v_{c}}=\frac{\hat{v}_{c}(s)}{\Delta i_{d}(s)}=-\frac{2 R I_{d}{ }^{*}+\omega P\left(L_{d}-L_{q}\right) I_{q}{ }^{*}}{s C\left(2 V_{c}^{*}-V_{0}\right)} \ldots \ldots
$$

(16) implies that the deviation of the capacitor voltage $\hat{v}_{c}$ is controllable by the fine tune control of the $d$-axis current and thus, it is possible to support both the controls of capacitor voltage and motor output together.

4.3 Control System Configuration of Proposed Drive System Figure 7 illustrates the control block diagram configured based on the examination in the preceding section. The field current controller employs a PI controller based on the error between its reference and detected values. The capacitor voltage controller is also composed of a PI controller based on the deviation between its reference and detected values. In addition, $\Delta i_{d}$ as the output of the capacitor voltage controller is delivered to the $d$-axis current controller so that the independent control of the capacitor voltage and the motor torque and output can be achieved. The WFSM controller takes control of each axis current with a PI controller by employing the decoupling control as with conventional AC machines. The proposed system has to be controlled by the appropriate control reference parameters $I_{f}{ }^{*}, V_{c}{ }^{*}, I_{d}{ }^{*}, I_{q}{ }^{*}$ taking into account the control constraint conditions under the given operating point $\left(\tau^{*}, \omega\right)$. For this reason, the sets of control reference parameters for the operating region are stored in a look-up table in advance.

\section{Control Constraint Conditions and Reference Parameter Search}

This chapter explains how to search for the control reference parameters to control the field current, the capacitor voltage and the motor output simultaneously at given operating points in the proposed system taking into account its constraints.

5.1 Constraint of Input-output Balance Equation in ZSI The steady-state input-output relation in the ZSI is expressed in the following equation with the control reference parameters of given operating points from energy conservation. 


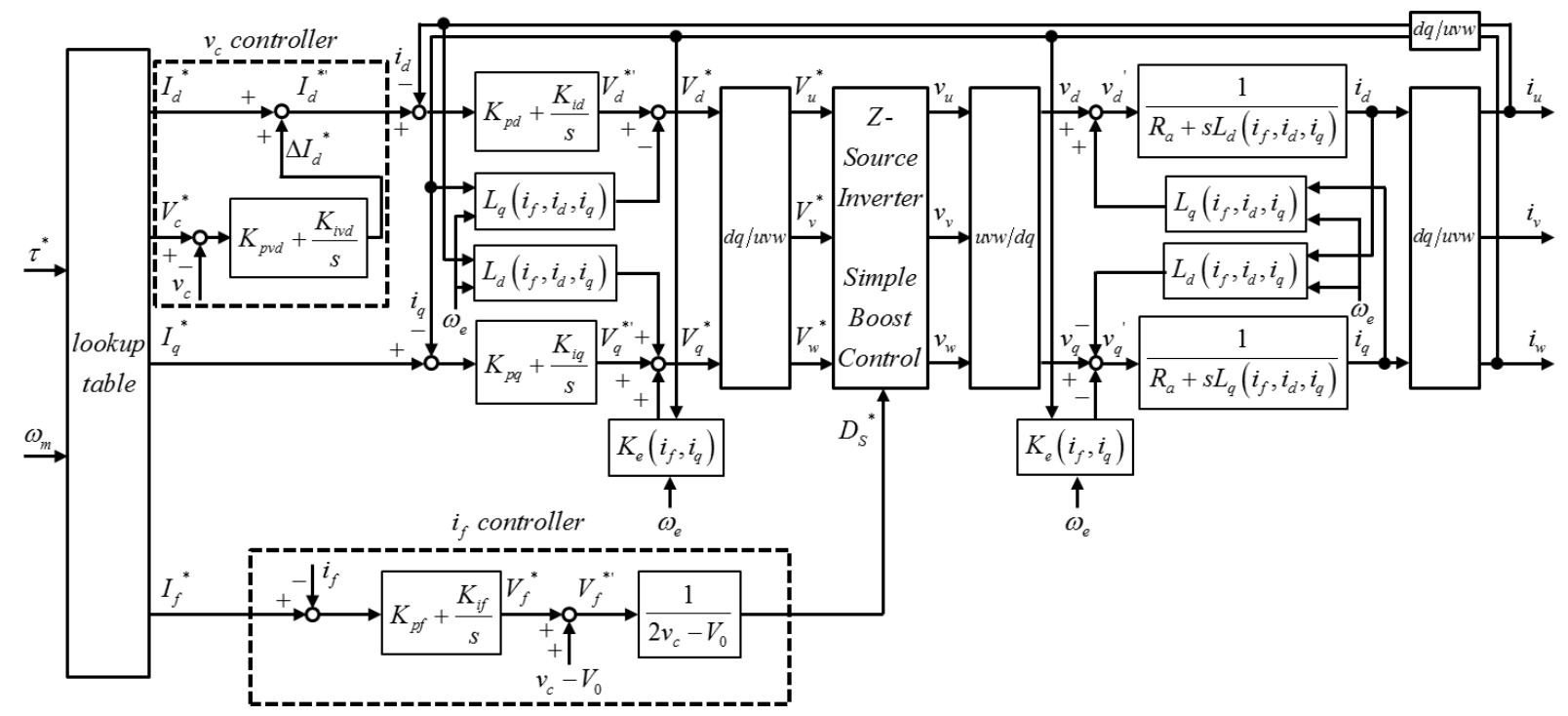

Fig. 7. Block diagram of the proposed controller

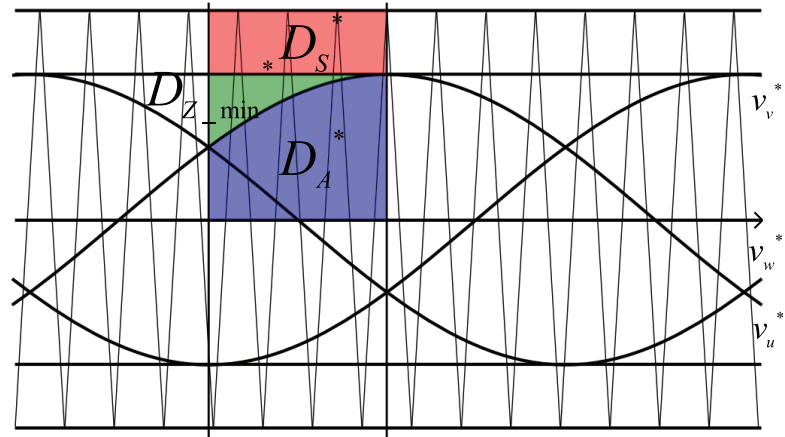

Fig. 8. Duty ratio of each operating state

$$
V_{0} I_{f}^{*}=2 R_{f} I_{f}^{* 2}+R\left(I_{d}^{* 2}+I_{q}^{* 2}\right)+\omega \tau^{*}
$$

The left-hand side of (17) expresses the input from the DC power source. The first term on the right side expresses the copper loss of the field coils. The second and third terms are the copper loss of armature windings and the motor output, respectively.

5.2 Constraint of Field Current Reference The field current reference $I_{f}{ }^{*}$ and the current $I_{i}$ being fed to inverter bridge at the active state have to satisfy the following equation to avoid the freewheeling diode shoot through state.

$$
2 I_{f}^{*}>I_{i}
$$

5.3 Constraint of Operable Duty Ratio The ZSI is controlled by the duty ratios of the three states. The control reference parameters have to be chosen such that the sum of the duty ratios at operating points does not exceed 1 . The following equation is obtained by rearranging (11).

$$
m^{*}=D_{A}{ }^{*}+D_{Z_{-} \min }{ }^{*} \leq 1-D_{S}{ }^{*} .
$$

Where $D_{Z \_ \text {min }}{ }^{*}$ is the minimum duty ratio reference of the active zero state. $m^{*}$ is the sum of $D_{A}{ }^{*}$ and $D_{Z \_ \text {min }}{ }^{*}$ and expressed by another equation below for the reason that the duty ratio equals the area ratio as shown in Fig. 8.

$$
m^{*}=\frac{2 \pi}{3 \sqrt{3}} D_{A}{ }^{*}
$$

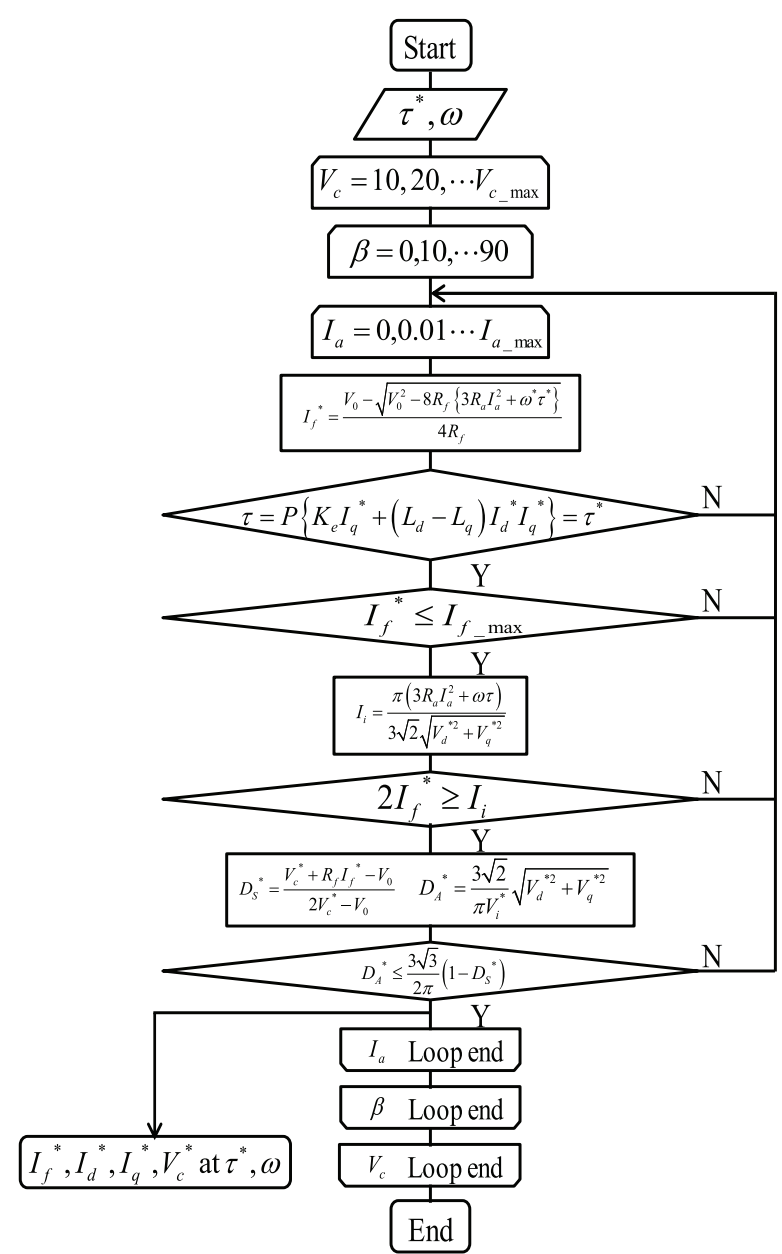

Fig. 9. Flowchart of control reference parameters search

Rearranging (19) and (20), the following equation is derived.

$$
D_{A}{ }^{*} \leq \frac{3 \sqrt{3}}{2 \pi}\left(1-D_{S}{ }^{*}\right)
$$

Thus, the ZSI has to be controlled such that the duty ratios $D_{A}{ }^{*}$ and $D_{S}{ }^{*}$ satisfy (21). 
5.4 Control Parameter Search at Given Motor Operating Points The flowchart of control reference parameters search at given operating points of the drive system of the WFSM integrated with the ZSI is shown in Fig. 9. The field current $I_{f}{ }^{*}$, the armature current $I_{d}{ }^{*}, I_{q}{ }^{*}$ and the capacitor voltage $V_{c} *$ as the control reference parameters satisfying the constraint conditions of (17), (18) and (21) is searched at given torque reference and motor speed condition. They are eventually stored in a look-up table.

\section{Experimental Results}

Experimental verifications of the proposed control algorithm are conducted using a test WFSM and a test ZSI as shown in Figs. 10 and 11. The measured WFSM parameters and the capacitance $C$ of impedance-network used in the ZSI appear in Table 1 . The dimensions of the main machine part of the WFSM are the outer diameter of $100 \mathrm{~mm}$ and the stack length of $26.6 \mathrm{~mm}$, respectively. The rated torque of the test
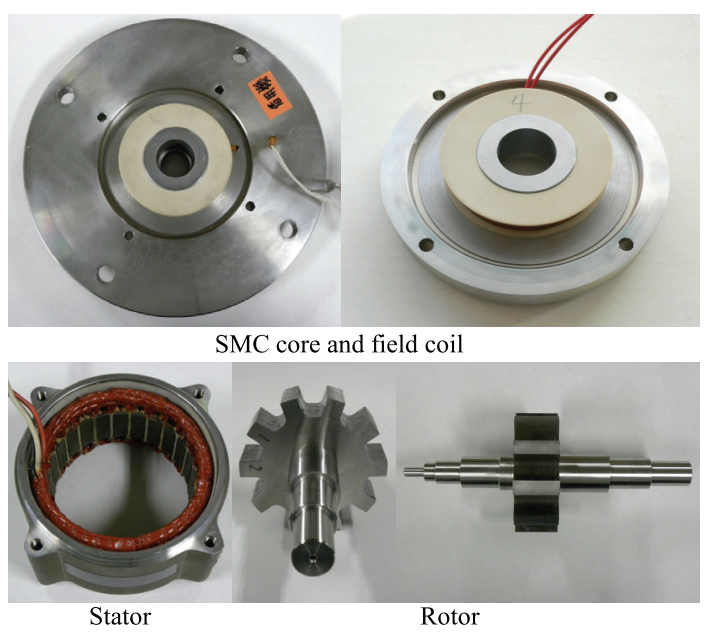

Fig. 10. Photographs of tested WFSM

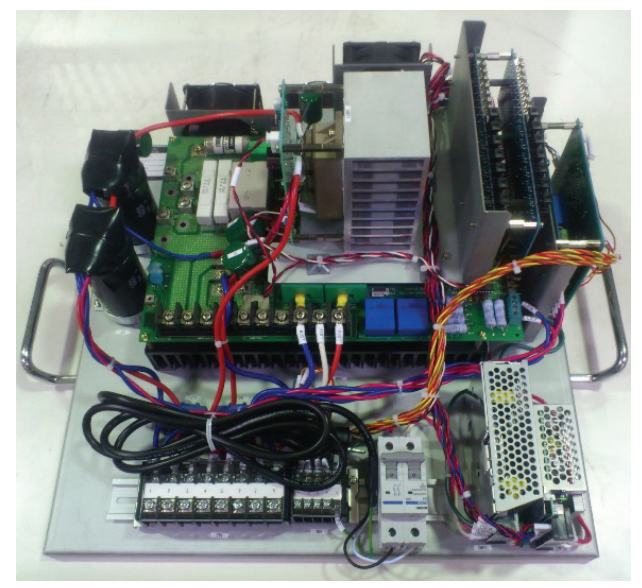

Fig. 11. Photographs of fabricated ZSI for test

Table 1. Measured parameters of WFSM and ZSI

\begin{tabular}{|c|c|c|}
\hline \multirow{4}{*}{$\begin{array}{c}\text { WFSM } \\
\text { machine } \\
\text { parameters }\end{array}$} & $R[\Omega]$ & $0.36 @ 20^{\circ} \mathrm{C}$ \\
\cline { 2 - 3 } & $L_{d}[\mathrm{mH}]$ & $0.82($ nominal) \\
\cline { 2 - 3 } & $L_{q}[\mathrm{mH}]$ & $0.98($ nominal) \\
\cline { 2 - 3 } & $R_{f}[\Omega]$ & $1.13 @ 20^{\circ} \mathrm{C}$ \\
\cline { 2 - 3 } & $L_{f}[\mathrm{mH}]$ & $30($ nominal) \\
\hline ZSI & $C[\mathrm{uF}]$ & 9.9 \\
\hline
\end{tabular}

WFSM is approximately $1.5 \mathrm{Nm}$ under ambient air cooling. The rated speed of the motor is 3,000 r/min when the conventional three-phase inverter with the rated DC bus voltage of $283 \mathrm{~V}$ is used. In experiments, the DC voltage source is set to $60 \mathrm{~V}$ constant in order to check voltage boost-up capability. Since the capacitor voltage $v_{c}$ is fluctuated owing to the use of a small capacitance of $9.9 \mu \mathrm{F}$, the maximum capacitor voltage limit is set to $130 \mathrm{~V}$ considering the withstand voltage of the switching devices in the inverter $(600 \mathrm{~V})$. This results in
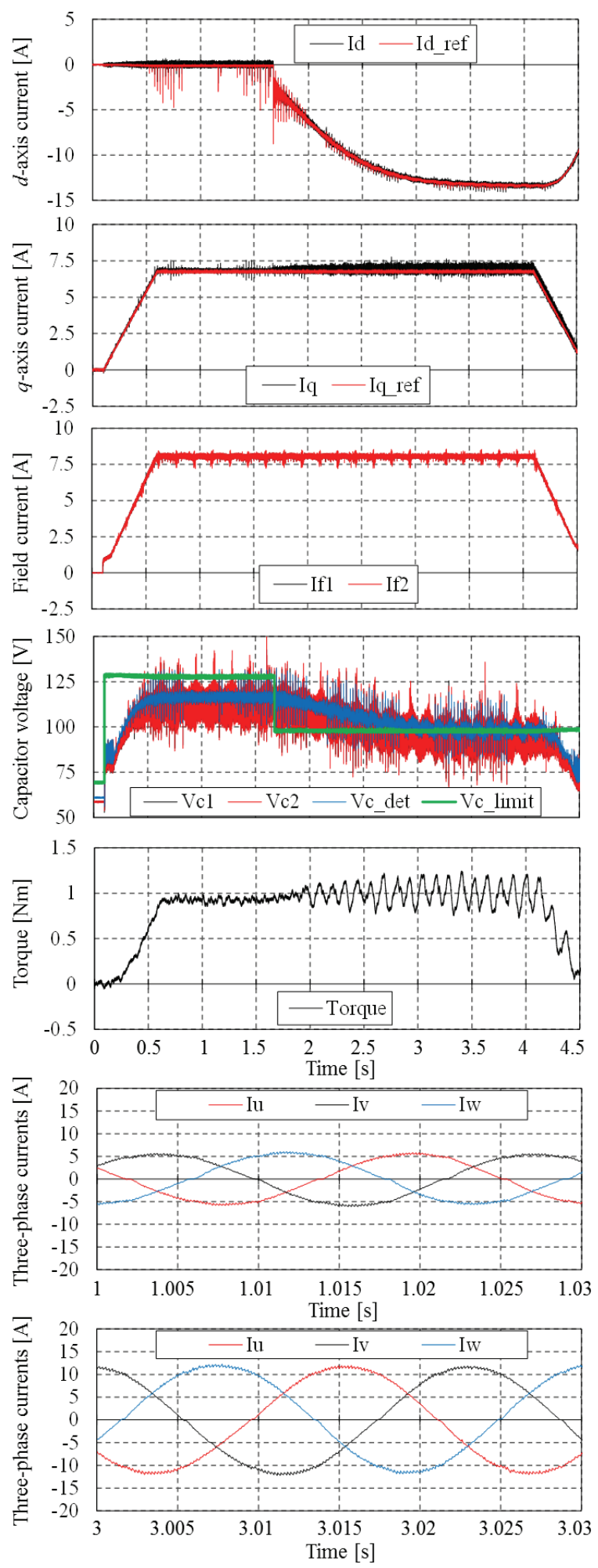

Fig. 12. Experimental result operating at $0.94 \mathrm{Nm}-250 \mathrm{r} / \mathrm{min}$ 

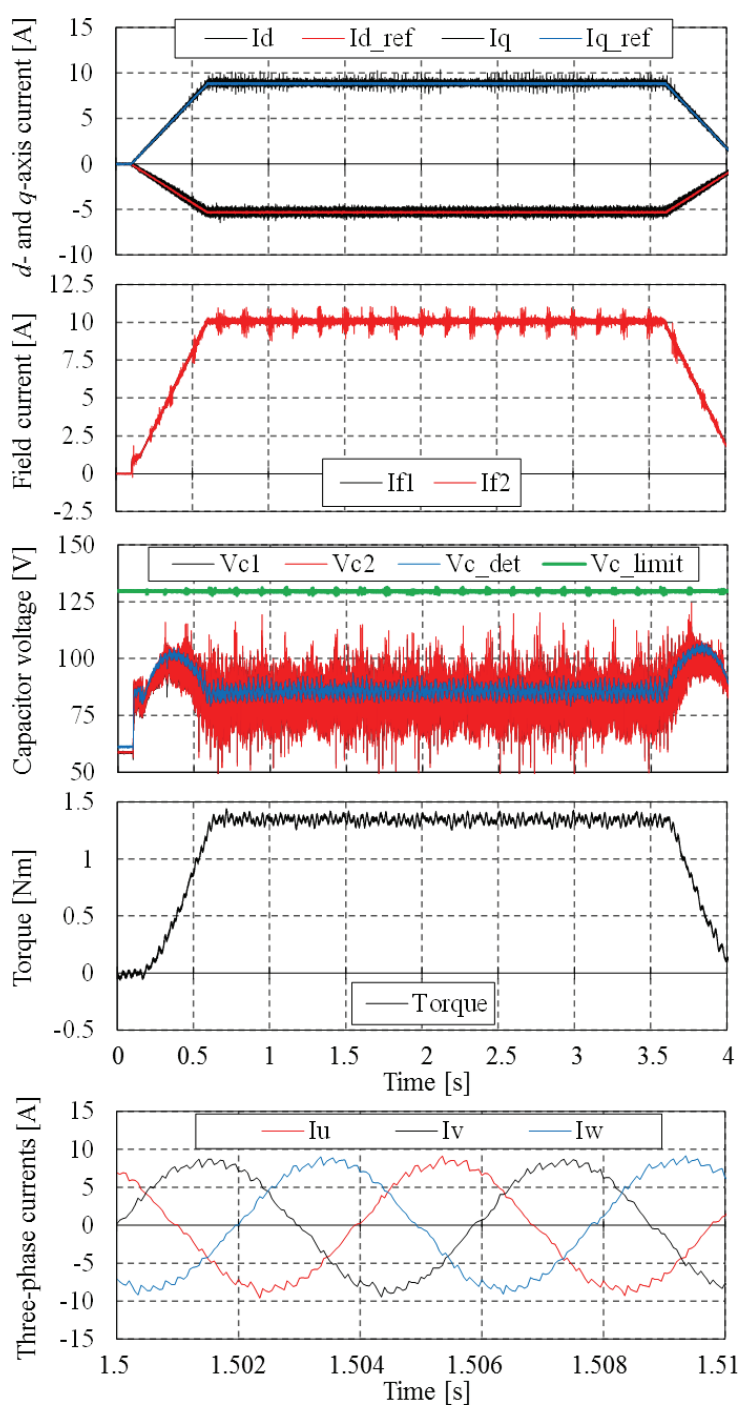

Fig. 13. Experimental result operating at $1.34 \mathrm{Nm}-1,000 \mathrm{r} / \mathrm{min}$

the maximum voltage across the inverter leg $v_{i}$ at the active state is $200 \mathrm{~V}$ as determined by (7). Thus, the rated motor speed is reduced by $2,000 \mathrm{r} / \mathrm{min}$. The test WFSM is in torque control mode under speed control by the dynamo side.

Figure 12 demonstrates the experimental result at $0.94 \mathrm{Nm}$ under $250 \mathrm{r} / \mathrm{min}$. The command values of $d$-axis current $I_{d}{ }^{*}$ and $q$-axis current $I_{q}{ }^{*}$ are set to $0 \mathrm{~A}$ and $6.8 \mathrm{~A}$, respectively. The field current command $I_{f}{ }^{*}$ is set to $8.0 \mathrm{~A}$. In this experiment, the maximum capacitor voltage limit is intentionally changed from $130 \mathrm{~V}$ to $100 \mathrm{~V}$ to verify the effectiveness of the proposed capacitor voltage control. It is found that all currents converge to their references. The actual capacitor voltages $V_{c 1}$ and $V_{c 2}$ are boosted more than $100 \mathrm{~V}$, resulting in the voltage across the inverter leg $v_{i}$ being more than $140 \mathrm{~V}$. The detected capacitor voltage $V_{c-\text { det }}$ in the controller follows the maximum capacitor voltage limit $V_{c \text {-limit }}$. Thus, it is concluded that the proposed capacitor voltage control works well. The two traces from the bottom in the figure show the three-phase current waveforms for the enlarged time scale during 1 to $1.03 \mathrm{~s}$ and 3 to $3.03 \mathrm{~s}$ before and after the maximum capacitor voltage limit change, respectively. As apparent from the waveforms, the three-phase currents are controlled pure sinusoidal. The torque ripple, which can be
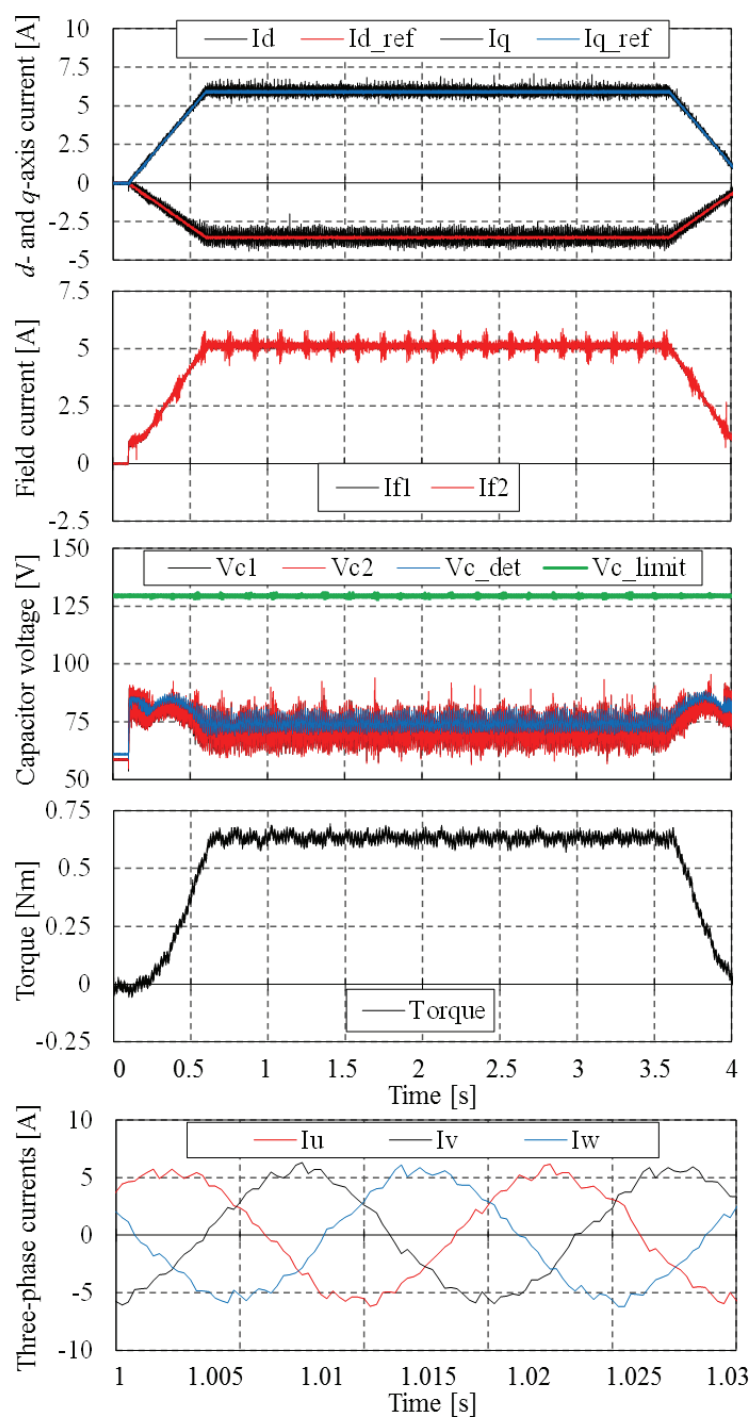

Fig. 14. Experimental result operating at $0.63 \mathrm{Nm}-2,000 \mathrm{r} / \mathrm{min}$

observed after starting the capacitor voltage control, would be due to low-frequency capacitor voltage ripple.

Figure 13 demonstrates the experimental result at an approximately rated torque of $1.34 \mathrm{Nm}$ under $1,000 \mathrm{r} / \mathrm{min}$. The command values of $d$-axis current $I_{d}{ }^{*}, q$-axis current $I_{q}{ }^{*}$ and field current $I_{f}{ }^{*}$ are $-5.2 \mathrm{~A}, 9.0 \mathrm{~A}$ and $10.0 \mathrm{~A}$, respectively. From the figure, it can be seen that all currents follow their references.

Figure 14 shows the experimental result at $0.63 \mathrm{Nm}$ under $2,000 \mathrm{r} / \mathrm{min}$. The command values of $d$-axis current $I_{d}{ }^{*}, q$ axis current $I_{q}{ }^{*}$ and field current $I_{f}{ }^{*}$ are $-3.5 \mathrm{~A}, 6.0 \mathrm{~A}$ and 5.0 A, respectively. From the figure, it can be found that all currents follow their references. Consequently, it is concluded that the proposed control algorithm is effective for operating the proposed drive system.

Here, Table 2 summarizes the comparisons of the motor efficiency and the losses of the tested motor at each operating point corresponding to Figs. 13 and 14 when the proposed drive system and a non-integrated drive system are used. The non-integrated drive system is composed of separated circuits such as a DC chopper for field coil excitation and a threephase inverter for feeding current to the armature windings. $P_{\min }$ is measured by a Yokogawa Digital Power Meter WT 
Table 2. Efficiency and losses with WFSM and ZSI-WFSM

\begin{tabular}{|c|c|c|c|c|c|}
\hline & \multicolumn{2}{|c|}{$1.34 \mathrm{Nm}-1,000 \mathrm{r} / \mathrm{min}$} & \multicolumn{2}{|c|}{$0.63 \mathrm{Nm}-2,000 \mathrm{r} / \mathrm{min}$} \\
\hline & & WFSM & ZSI-WFSM & WFSM & ZSI-WFSM \\
\hline \multicolumn{2}{|c|}{ Motor input $P_{\min }$} & $425 \mathrm{~W}$ & $429 \mathrm{~W}$ & $212 \mathrm{~W}$ & $220 \mathrm{~W}$ \\
\hline \multicolumn{2}{|c|}{ Motor output $P_{\text {mout }}$} & $137 \mathrm{~W}$ & $139 \mathrm{~W}$ & $123 \mathrm{~W}$ & $131 \mathrm{~W}$ \\
\hline \multirow{2}{*}{$\begin{array}{c}\text { Copper } \\
\text { loss }\end{array}$} & Armature w.d.g. $P_{c c}$ & $38 \mathrm{~W}$ & $39 \mathrm{~W}$ & $17 \mathrm{~W}$ & $17 \mathrm{~W}$ \\
\hline & Field coils $P_{c f}$ & $224 \mathrm{~W}$ & $231 \mathrm{~W}$ & $57 \mathrm{~W}$ & $60 \mathrm{~W}$ \\
\hline \multicolumn{2}{|c|}{ Mechanical loss $P_{\text {mech }}$} & $4 \mathrm{~W}$ & $4 \mathrm{~W}$ & $6 \mathrm{~W}$ & $6 \mathrm{~W}$ \\
\hline \multicolumn{2}{|c|}{ Residual loss $P_{r e s}$} & $22 \mathrm{~W}$ & $17 \mathrm{~W}$ & $9 \mathrm{~W}$ & $6 \mathrm{~W}$ \\
\hline \multicolumn{2}{|c|}{ Motor efficiency } & $32.2 \%$ & $32.4 \%$ & $58.0 \%$ & $59.5 \%$ \\
\hline \multicolumn{2}{|c|}{ Motor power factor } & 0.892 & 0.928 & 0.919 & 0.935 \\
\hline
\end{tabular}

1600. $P_{\text {mout }}$ is calculated from the motor speed and the average torque measured by the dynamo setup, Ono Sokki, TS7700. $P_{c a}$ and $P_{c f}$ are calculated by the resistances in Table 1 and the measured rms currents of the armature windings and DC current of the field windings. $P_{\text {mech }}$ is also premeasured by the dynamo setup. The motor efficiency and the motor power factor of the proposed integrated WFSM are slightly higher than those of the non-integrated WFSM. In the table, the residual loss $P_{\text {res }}$ is calculated from the following equation.

$$
P_{\text {res }}=P_{\text {min }}-P_{\text {mout }}-P_{c a}-P_{c f}-P_{\text {mech }} \cdots \cdots \cdots
$$

Generally, the residual loss is regarded as the iron loss. The residual loss of the WFSM coupled in the proposed drive system is slightly smaller than that in the non-integrated drive system. As a result, it is reasonable to say that the WFSM coupled in the proposed integrated drive system can keep equivalent drive performances with those in the nonintegrated drive system.

\section{Conclusions}

This paper has proposed a variable motor drive system, a WFSM integrated with a ZSI. The basic working principle of the proposed integrated drive system has been explained. To solve the problem of reduced control freedom in the proposed integrated drive system, a control algorithm employing $d$-axis current control has been proposed. Some experimental tests have been conducted that verified the validity of the proposed control algorithm. In future studies, we will clarify the design procedure of the proposed integrated drive system for a specific application and will evaluate the advantages from the viewpoints of system efficiency as well as cost and size reduction.

\section{References}

( 1 ) T. Kosaka, T. Hirose, and N. Matsui: "Brushless Synchronous Machines with Wound-Field Excitation using SMC Core Designed for HEV Drives", Proc. of the 2010 International Conference on Power Electronics (IPEC-Sapporo), No.23G2-1, pp.1794-1800 (2010)

( 2 ) M. Kamiya: "Development of Traction Drive Motors for the Toyota Hybrid Systems", IEEJ Trans. IA, Vol.126, No.4, pp.473-479 (2006)

( 3 ) F.Z. Peng: "Z-Source Inverter", IEEJ Trans. IA, Vol.39, No.2, pp.504-510 (2003)

( 4 ) M. Shen and F.Z. Peng: "Operation Modes and Characteristics of the ZSource Inverter With Small Inductance of Low Power Factor", IEEE Trans. Ind. Electron., Vol.55, No.1, pp.89-96 (2008)

( 5 ) J. Liu, J. Hu, and L. Xu: "Dynamic Modeling and Analysis of Z Source Converter-Derivation of AC Small Signal Model and Design Oriented Analysis", IEEE Trans. on Power Electronics, Vol.22, No.5, pp.1786-1796 (2007)
Genki Tajima (Student Member) was born in Aichi, Japan, in 1989.

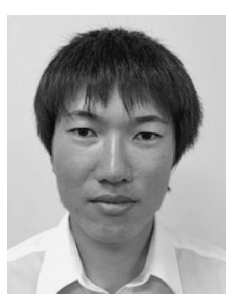
He received the B.S. and M.S. degrees from Nagoya Institute of Technology, Nagoya, Japan in 2012 and 2014, respectively. He is currently working towards his Ph.D. degree in the Department of Computer Science and Engineering, Nagoya Institute of Technology. His main research interests are design and control of drive system integrated with motor and driving circuit.

Takashi Kosaka (Senior Member) was born in Aichi, Japan, on De-

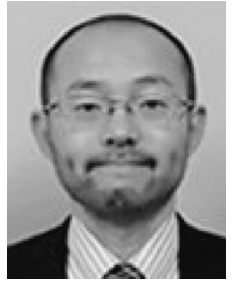
cember 29, 1968. He also received his B.S., M.S. and $\mathrm{Ph} . \mathrm{D}$. degrees in electrical and computer engineering from NITech, Nagoya, Japan, in 1994, 1996, and 1999, respectively. Since 1999, he has been with the Dept. of Electrical and Computer Eng., NITech, where he is currently an Associate Professor. From 2002 to 2004, he was with the University of Leicester, U.K, as visiting research fellow supported by the Japan Society for the Promotion of Science. His current research interests include design and control of application-oriented electrical machines. Dr. Kosaka is a member of the IEEE and IEEJ.

Nobuyuki Matsui (Fellow) was born in Wakayama, Japan, on May

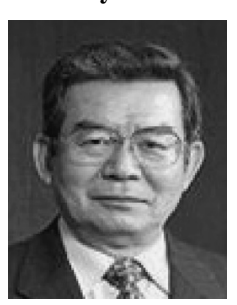
7, 1943. He received his B.S. and M.S. degrees in electrical engineering from NITech, Nagoya, Japan, in 1966 and 1968, respectively and the Ph.D. degree from Tokyo Institute of Technology, Tokyo, Japan, in 1976. Since 1968, he has been with the Dept. of Electrical and Computer Eng., NITech. As a Professor, he has been engaged in research and education on power electronics and motion control. From April 2000 to October 2002, he was Vice-President of NITech. From January 2004 to March 2010, he served as the President of NITech. From 2010, he has been granted the title of emeritus professor in NITech. He is fellow of the IEEE and IEE Japan and he was awarded IEEE IAS 2005 Outstanding Achievement Award.

Kazuki Tonogi (Non-member) was born in Aichi, Japan, on Novem-

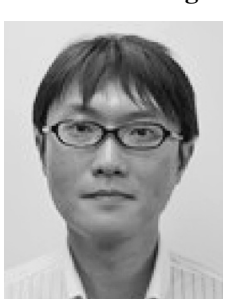
ber 9, 1983. He received his B.S., M.S. degrees in electrical and computer engineering from NITech, Nagoya, Japan, in 2006, 2008, respectively. He joined Toyota Industries Corporation in 2008. He has been engaged in research and development of power electronics and motor drive systems.

Norimoto Minoshima (Non-member) was born in Aichi, Japan, on

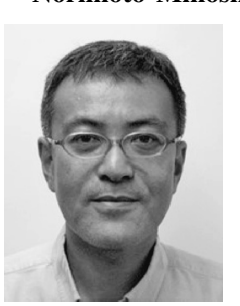
November 14, 1970. He received his B.S. degrees in electrical and computer engineering from NITech, Nagoya, Japan, in 1993. He joined Toyoda Automatic Loom Works, Ltd. Current name Toyota Industries Corporation in 1993. He has been engaged in research and development of power electronics and motor drive systems.

Toshihiko Yoshida (Non-member) was born in Shizuoka, Japan, on

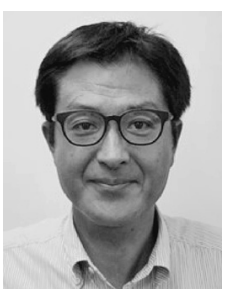
October 14, 1961. He received the B.S. in applied physics from National Defense Academy of Japan, Kanagawa, Japan, in 1984. He joined Toyoda Automatic Loom Works, Ltd. Current name Toyoda Industries Corporation in 1984. He has been engaged in research and development of power electronics and motor drive systems. 